\title{
Interpretation of viscometer test results for polymer support fluids
}

DOI:

$10.1061 / 9780784413449.043$

Link to publication record in Manchester Research Explorer

\section{Citation for published version (APA):}

Lam, C., \& Jefferis, S. A. (2014). Interpretation of viscometer test results for polymer support fluids. In Geotechnical Special Publication/Geotech Spec Publ (pp. 439-449). American Society of Civil Engineers. https://doi.org/10.1061/9780784413449.043

\section{Published in:}

Geotechnical Special Publication|Geotech Spec Publ

\section{Citing this paper}

Please note that where the full-text provided on Manchester Research Explorer is the Author Accepted Manuscript or Proof version this may differ from the final Published version. If citing, it is advised that you check and use the publisher's definitive version.

\section{General rights}

Copyright and moral rights for the publications made accessible in the Research Explorer are retained by the authors and/or other copyright owners and it is a condition of accessing publications that users recognise and abide by the legal requirements associated with these rights.

\section{Takedown policy}

If you believe that this document breaches copyright please refer to the University of Manchester's Takedown Procedures [http://man.ac.uk/04Y6Bo] or contact uml.scholarlycommunications@manchester.ac.uk providing relevant details, so we can investigate your claim.

\section{OPEN ACCESS}




\title{
Interpretation of Viscometer Test Results for Polymer Support Fluids
}

\author{
Carlos Lam $^{1}$ and Stephan A. Jefferis ${ }^{2}$ \\ ${ }^{1}$ Lecturer, School of Mechanical, Aerospace and Civil Engineering, The University of \\ Manchester, Manchester, M13 9PL, U.K.; carlos.lam@manchester.ac.uk \\ ${ }^{2}$ Director, Environmental Geotechnics Ltd, St Mary’s Grove, 4 Adderbury Park, \\ Adderbury, Banbury, OX17 3EN, U.K.; Visiting Professor, Department of \\ Engineering Science, University of Oxford, Parks Road, Oxford, OX1 3PJ, U.K.; \\ egl@environmentalgeotechnics.com
}

ABSTRACT: Polymer support fluids have been successfully used for the construction of bored piles (drilled shafts) and diaphragm walls for many years and yet there is currently little guidance on the interpretation of their rheological properties from viscometer test results. In particular, there is confusion about the choice of an appropriate rheological model for this type of fluid. The use of oilfield units by some has also added to the confusion. To promote the use of SI units, this paper summarizes conversion factors that can be used to present viscometer data in a more uniform manner. Simple rheological concepts and instrument-specific equations are also given for those unfamiliar with the issues. Viscometer test results for two polymers fluids are then used to illustrate the application of the power-law model over the shear-rate range achievable with a typical direct-indicating viscometer.

\section{INTRODUCTION}

Direct-indicating viscometers have been used for the testing of excavation-support fluids for many decades. These instruments are based on the operating principle of the concentric cylinders viscometer and the design of Savins and Roper (1954). This design is such that the two parameters of the Bingham plastic fluid model, namely plastic viscosity and yield point, can be very simply calculated from the dial readings at rotor speeds of 300 and $600 \mathrm{r} / \mathrm{min}$. This feature greatly simplifies the interpretation of viscometer results in the field as curve-fitting is not required. Figure 1 shows a photograph of a variable speed model and a schematic diagram of the key components. Most direct-indicating viscometers used in construction today are either hand-cranked two-speed (300 and $600 \mathrm{r} / \mathrm{min}$ ) or electrically driven six-speed (3, 6, 100, 200, 300 and 600 r/min) models. The Fann Instrument Company has been a major manufacturer of this type of direct-indicating viscometer since the days of the 
original design so that in the industry this type of viscometer is commonly referred to as the Fann viscometer.

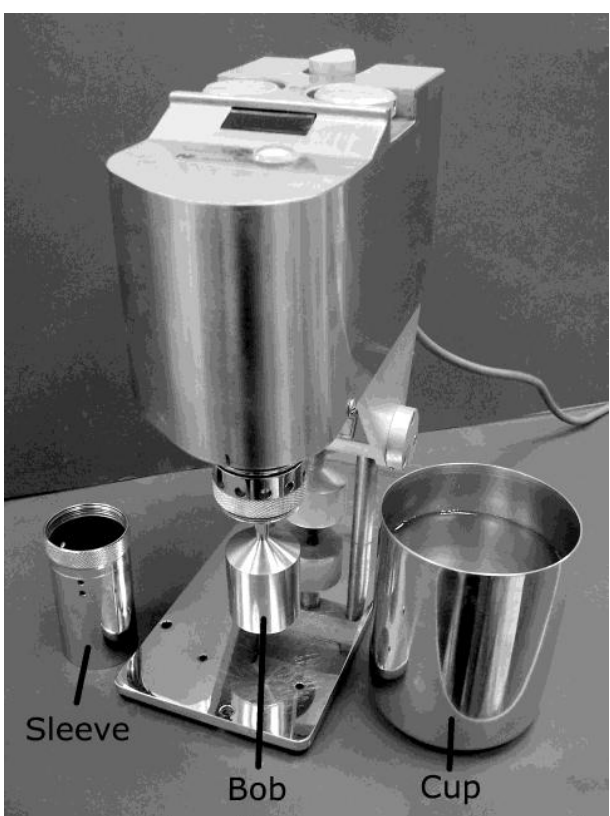

(a)

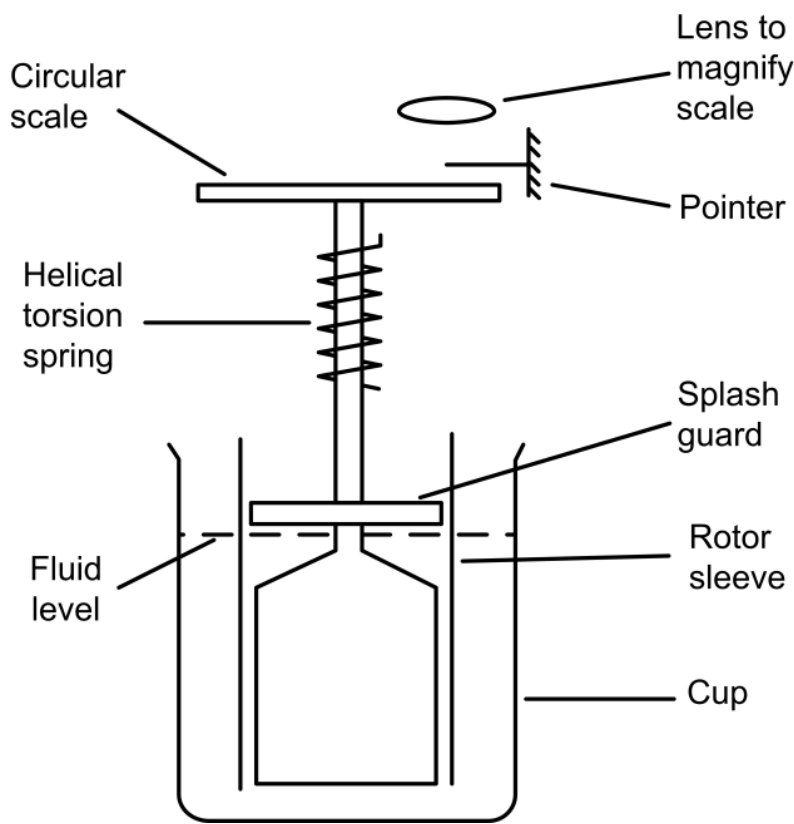

(b)

FIG. 1. Direct-indicating viscometer: (a) photograph of a variable speed model; (b) schematic diagram

Piling and diaphragm walling excavations traditionally have been carried out using bentonite slurry whose flow behavior is often approximated by the Bingham plastic model. The interpretation of direct-indicating viscometer results for this type of fluid has not been an issue. However, since the early 1990s, synthetic polymer fluids have been used successfully in many projects around the world (e.g. Lam et al. 2010; Jefferis and Lam 2013; Lam et al. 2014). The flow behavior of polymer fluids is very different from that of their bentonite counterpart and yet no distinction is currently made between the two types of fluid in terms of the interpretation of viscometer results. For example, in the Federal Highway Administration (FHWA) drilled shaft manual (O’Neill and Reese 1999; Brown et al. 2010), a set of viscometer results for a polymer fluid is used to illustrate interpretation methods. Figure 2 reproduces the plot and shows the interpreted results. It can be seen that the data points were fitted with both Bingham plastic and power-law models, though it is clear that the latter was able to provide a much better fit over the full data range.

The use of the Bingham plastic model to interpret polymer viscosity data can be traced back to studies in the 1990s when the polymer fluid technology was still in its infancy (e.g. Kheng et al. 1991; Majano et al. 1994; Ata and O’Neill 1997). It appears to be a carry-over from bentonite experience despite the fact that a power law model is more appropriate. In the authors' opinion, it is now the time to break away from the influence of bentonite and to adopt interpretation procedures which are appropriate 
for polymer fluids - recognizing that both Bingham and power-law models are datafitting equations and for any rheological modelling exercise the model that best fits the data should be used. It is therefore the aim of this paper to promote this idea by showing the excellent fit that the power-law model can provide for polymer viscosity data from different sources.

In addition, since the direct-indicating viscometer was originally developed for use in the petroleum industry in the U.S., the stress indication as shown on the dial of instrument is in $\mathrm{lb} / 100 \mathrm{ft}^{2}$ (pound per 100 square feet). This is an unfamiliar unit for most civil engineers especially those outside the U.S. The second aim of this paper is to promote the use of SI units in data presentation by using simple conversion factors. If the two aims of this paper are met, the presentation and interpretation of viscometer results can be standardized across different countries, thus making it easier for data and transfer and use.

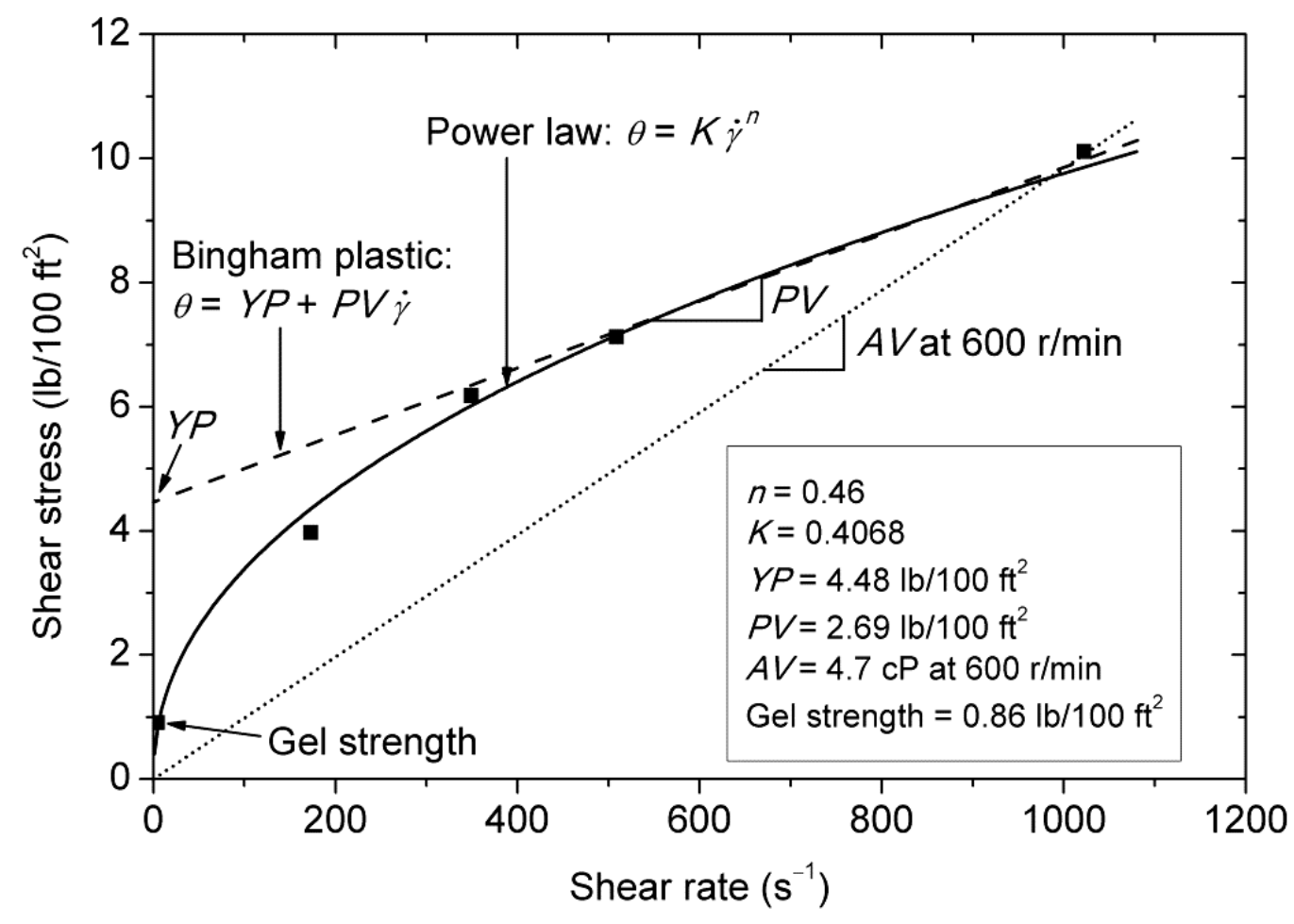

FIG. 2. Viscometer test results and interpretation for a polymer support fluid given in the FHWA drilled shaft manual (redrawn after O'Neill and Reese 1999; Brown et al. 2010)

\section{FUNDAMENTALS}

Before proceeding to the discussion of data interpretation, it is necessary to introduce some key concepts and terminology commonly associated with the study of fluid behavior involving the use of a direct-indicating viscometer. 


\section{Units}

The dial reading on the Fann direct-indicating viscometer is in $1 b / 100 \mathrm{ft}^{2}$, but note that the dial reading is not exact; one division on the dial actually equates to $1.065 \mathrm{lb} / 100 \mathrm{ft}^{2}$ (Fann Instrument Company 2013). The unit $\mathrm{lb} / 100 \mathrm{ft}^{2}$ is commonly used in the oilfields for shear stress and it can be converted to $\mathrm{Pa}\left(\mathrm{N} / \mathrm{m}^{2}\right)$ by multiplying the corrected dial readings by 0.48 or by 0.51 if using uncorrected dial readings - note this subtle difference is not mentioned in industry manuals such as Federation of Piling Specialists (2006), O’Neill and Reese (1999) and Brown et al. (2010). For the standard bob and rotor geometry, the shear rate at the bob in reciprocal seconds $\left(\mathrm{s}^{-1}\right)$ can be obtained by multiplying the rotor speed in $\mathrm{r} / \mathrm{min}$ 1.703. The viscosity of the test fluid is commonly expressed in $\mathrm{cP}$ (centipoise), which is numerically the same as the $\mathrm{SI}$ unit $\mathrm{mPa} \cdot \mathrm{s}$ (millipascal-second).

In the oil industry, viscometer results are still commonly presented in their original units, i.e., shear stress in $\mathrm{lb} / 100 \mathrm{ft}^{2}$ and rotor speed in $\mathrm{r} / \mathrm{min}$ (Caenn et al. 2011) although drilling fluid standards prefer SI units. In the construction industry, the situation is more confused as currently there are no agreed and standard units for the presentation of viscometer results. Ata and O'Neill (1997) reported their shear stress results in $\mathrm{lb} / 100 \mathrm{ft}^{2}$ and shear rates in $\mathrm{s}^{-1}$, whereas in Ata and O'Neill (1998) results were presented in $\mathrm{Pa}$ and $\mathrm{s}^{-1}$. Although the particular choice of units is not in itself a problem, it does make the use data from different sources more cumbersome especially for those who are less experienced. This is the reason why the Authors propose to standardize the practice by using only SI units.

\section{Basic rheological concepts}

The shear viscosity of a fluid $(\mu)$ at shear rate $\dot{\gamma}$ is defined as follows:

$$
\mu=\frac{\tau}{\dot{\gamma}}
$$

where $\tau$ is the shear stress at the given shear rate. For Newtonian fluids $\mu$ is a constant but for non-Newtonian fluids it will be a function of the prevailing shear rate and shear history, and hence the viscosity measured at any particular shear rate is often referred to as an 'apparent' or 'effective' viscosity. When citing results both the apparent viscosity and the shear rate at which it was measured should be given. Many mathematical models have been proposed to fit the $\tau-\dot{\gamma}$ relationship of non-

Newtonian fluids. Among these, the Bingham plastic and the power-law models are commonly used to fit viscoplastic and shear-thinning fluid behavior, respectively. Equations for these models are:

Bingham plastic: $\quad \tau=\tau_{0}+\mu_{\mathrm{p}} \dot{\gamma}$

Power law:

$\tau=K \dot{\gamma}^{n}$ 
where $\tau_{0}$ is the yield stress, $\mu_{\mathrm{p}}$ is the plastic viscosity, $K$ is the flow consistency coefficient and $n$ is the flow behavior index. In the industry, $\tau_{0}$ and $\mu_{\mathrm{p}}$ are commonly referred to as $Y P$ (yield point) and $P V$ (plastic viscosity) respectively (see Fig. 2). Substituting Eqs. 2 and 3 into Eq. 1 gives equations for apparent viscosity as a function of shear rate for the two models:

Bingham plastic: $\quad \mu=\frac{\tau_{0}}{\dot{\gamma}}+\mu_{\mathrm{p}}$

Power law:

$$
\mu=K \dot{\gamma}^{n-1}
$$

\section{Calculation of rheological model parameters directly from viscometer results}

The direct-indicating viscometer was designed so that the parameters of the Bingham plastic model, $P V$ and $Y P$, could be obtained directly from measured readings without the necessity for graphical plots. The equations for the instrument are:

$$
\begin{gathered}
P V=\mu_{\mathrm{p}}=\theta_{600}-\theta_{300} \\
Y P=\tau_{0}=\theta_{300}-P V=2 \theta_{300}-\theta_{600}
\end{gathered}
$$

where $\theta$ is the dial reading and the numeric subscripts indicate the rotor speed in $\mathrm{r} / \mathrm{min}$. Note $P V$ is in $\mathrm{mPa} \cdot \mathrm{s}$ and $Y P$ in $\mathrm{lb} / 100 \mathrm{ft}^{2}$. The 1.065 correction factor may be applied to the $Y P$ determined from Eq. 7. The design of the instrument also allows direct computation of the apparent viscosity in $\mathrm{mPa} \cdot \mathrm{s}(\mathrm{cP})$ at any rotor speed using the following equation:

$$
\mu=k \times f \times \frac{\theta}{\omega}
$$

where $\omega$ is the rotor speed in $\mathrm{r} / \mathrm{min}, k$ is the overall instrument constant and $f$ is the torsion spring factor. The value of $k$ is 300 for the standard rotor-bob combination R1-B1 - see Appendix for the derivation of this value. The value of $f$ is 1 for the standard torsion spring F1 (spring constant equals 386 dyne-cm/degree deflection). Therefore, the dial reading at $300 \mathrm{r} / \mathrm{min}$ is numerically equivalent to the viscosity of the fluid in $\mathrm{mPa} \cdot \mathrm{s}$; hence the name direct-indicating viscometer. In the literature, the most commonly quoted apparent viscosity, termed the $A V$, is that measured at a rotor speed of $600 \mathrm{r} / \mathrm{min}$ (Fig. 1). Substituting $\omega=600$ into Eq. 8 gives:

$$
A V=\frac{300 \times \theta_{600}}{600}=\frac{\theta_{600}}{2}
$$


It should be noted that Eqs. 6, 7 and 9 are simplified equations for a Fann viscometer equipped with the standard rotor, bob and torsion spring, that is rotor R1, bob B1 and torsion spring F1 (Fann Instrument Company 2013). Beresford et al. (1989) used a Fann viscometer with a different torsion spring (F0.2) and derived viscosity multipliers $(k \times f / \omega)$ for this setup which were again reported in Ata and O'Neill (1997). It should be emphasized that these multipliers should not be used for other data unless the same rotor, bob and spring combination is used.

The $\tau-\dot{\gamma}$ relationship of the power-law model is linear on a log-log plot; taking advantage of this feature the two model parameters $n$ and $K$ (Eq. 3) can be estimated directly from the dial readings (for example, at 300 and $600 \mathrm{r} / \mathrm{min}$ though other speeds can be used), as follows:

$$
\begin{gathered}
n=\frac{\log \theta_{600}-\log \theta_{300}}{\log \omega_{600}-\log \omega_{300}}=3.32 \log \frac{\theta_{600}}{\theta_{300}} \\
K=\frac{\tau}{\dot{\gamma}^{n}}=\frac{\theta_{600}}{1022^{n}}
\end{gathered}
$$

where $\theta$ is the dial reading in $\mathrm{lb} / 100 \mathrm{ft}^{2}, n$ is dimensionless and $K$ is in $\mathrm{lb} / 100 \mathrm{ft}^{2} \cdot \mathrm{s}^{n}$, which can be converted into $\mathrm{Pa} \cdot \mathrm{s}^{n}$ by multiplying 0.48 or 0.51 depending on whether $\theta_{600}$ has been corrected. Note the unit of $K$ is dependent on the value of $n$.

\section{INTERPRETATION OF POLYMER VISCOSITY RESULTS}

To demonstrate the usefulness of the power-law model for interpreting polymer viscosity data, a set of viscometer results for a PHPA (partially hydrolyzed polyacrylamide) fluid is used as an example. This polymer, CDP from KB International, has a molecular weight of $20 \times 10^{6} \mathrm{~g} / \mathrm{mol}$ and a degree of hydrolysis of $40 \%$ (Goodhue and Holmes, 1995). The test fluid was mixed at a concentration of $0.8 \mathrm{~kg} / \mathrm{m}^{3}$ using deionized water and a low-shear laboratory mixer. Table 1 summarizes the raw test results and calculated shear stresses, shear rates and viscosities in SI units. Either Eq. 1 (from first principles) or Eq. 8 (direct from uncorrected dial readings) can be used as they will give the same result.

Table 2 also lists the power-law parameters calculated by the two-point quick method (using Eqs. 10 and 11 and thus rotational speeds of 300 and $600 \mathrm{r} / \mathrm{min}$ ) and by the best fit to a curve generated from a fuller set of data points for speeds between 3 and $600 \mathrm{r} / \mathrm{min}$. It can be seen that although the two $n$ values are in reasonable agreement, the difference between the $K$ values is much greater. The use of Eqs. 10 and 11 is therefore not recommended for precise work, though they may still be useful in the field to identify shear-thinning behavior as shown by a value of $n<1$. The use of 300 and $600 \mathrm{r} / \mathrm{min}$ data is now well accepted for interpretation of data on 
support fluids which show Bingham behavior but a wider range of speeds is recommended for power-law fluids.

Table 1. Viscosity Results for a 'CDP' Polymer Support Fluid

\begin{tabular}{|c|c|c|c|c|}
\hline \multicolumn{2}{|c|}{ Raw data } & \multicolumn{3}{|c|}{ Interpretation } \\
\hline $\begin{array}{c}\text { Rotor } \\
\text { Speed, } \boldsymbol{\omega} \\
(\mathbf{r} / \mathbf{m i n})\end{array}$ & $\begin{array}{c}\text { Dial } \\
\text { Reading, } \boldsymbol{\theta} \\
\left(\mathbf{l b} / \mathbf{1 0 0} \mathbf{f t}^{\mathbf{2}}\right)\end{array}$ & $\begin{array}{c}\text { Shear } \\
\text { Rate, } \dot{\gamma} \\
\left(\mathbf{s}^{-\mathbf{1}}\right)\end{array}$ & $\begin{array}{c}\text { Shear } \\
\text { Stress, } \boldsymbol{\tau} \\
(\mathbf{P a})\end{array}$ & $\begin{array}{c}\text { Viscosity, } \boldsymbol{\mu} \\
(\mathbf{m P a} \cdot \mathbf{s})\end{array}$ \\
\hline 3 & 1.5 & 5.11 & 0.77 & 150.0 \\
\hline 6 & 2 & 10.22 & 1.02 & 100.0 \\
\hline 100 & 7 & 170.30 & 3.58 & 21.0 \\
\hline 200 & 11 & 340.60 & 5.62 & 16.5 \\
\hline 300 & 14 & 510.90 & 7.15 & 14.0 \\
\hline 600 & 21 & 1021.80 & 10.74 & 10.5 \\
\hline
\end{tabular}

Table 2. Power-Law Parameters for a 'CDP' Polymer Support Fluid

\begin{tabular}{|c|c|c|}
\hline $\begin{array}{c}\text { Calculation } \\
\text { Method }\end{array}$ & $\begin{array}{c}\text { Flow Behavior Index, } \boldsymbol{n} \\
(-)\end{array}$ & $\begin{array}{c}\text { Flow Consistency Index, } \boldsymbol{K} \\
\left(\mathbf{P a} \cdot \mathbf{s}^{\boldsymbol{n}} \mathbf{)}\right.\end{array}$ \\
\hline Eqs. 10 and 11 & 0.585 & 0.187 \\
\hline Curve Fitting & 0.491 & 0.327 \\
\hline
\end{tabular}

To confirm the validity of the power law for other polymers, the viscometer test results for the 'visKeau' polymer given in Beresford et al. (1989) are used and are given in Table 3.

Table 3. Viscosity Results for a 'visKeau' Polymer Support Fluid (data from Beresford et al. 1989)

\begin{tabular}{|c|c|c|c|c|c|}
\hline \multicolumn{5}{|c|}{ From Beresford et al. (1989) } & $\begin{array}{c}\text { Computed by } \\
\text { the Authors }\end{array}$ \\
\hline $\begin{array}{c}\text { Rotor } \\
\text { Speed, } \boldsymbol{\omega} \\
(\mathbf{r} / \mathbf{m i n})\end{array}$ & $\begin{array}{c}\text { Dial } \\
\text { Reading, } \boldsymbol{\theta} \\
\left(\mathbf{l b} / \mathbf{1 0 0} \mathbf{f t}^{\mathbf{2}}\right)\end{array}$ & $\begin{array}{c}\text { Shear } \\
\text { Rate, } \\
\dot{\gamma}\left(\mathbf{s}^{-\mathbf{1}}\right)\end{array}$ & $\begin{array}{c}\text { Viscosity } \\
\text { Multiplier } \\
(\boldsymbol{k} \times \boldsymbol{f}) / \boldsymbol{\omega}^{*}\end{array}$ & $\begin{array}{c}\text { Viscosity, } \boldsymbol{\mu} \\
(\boldsymbol{k} \times \boldsymbol{f} \times \boldsymbol{\theta}) / \boldsymbol{\omega} \\
(\mathbf{m P a} \cdot \mathbf{s})\end{array}$ & $\begin{array}{c}\text { Shear Stress, } \\
\boldsymbol{\tau}=\boldsymbol{\mu} \times \dot{\gamma} / 1000 \\
(\mathbf{P a})\end{array}$ \\
\hline 3 & 19.5 & 5.11 & 20 & 390 & 1.99 \\
\hline 6 & 23 & 10.22 & 10 & 230 & 2.35 \\
\hline 100 & 45 & 170.30 & 0.6 & 27 & 4.6 \\
\hline 200 & 37 & 340.60 & 0.3 & 10.8 & 3.78 \\
\hline 300 & 51 & 510.90 & 0.2 & 10.2 & 5.21 \\
\hline 600 & 73 & 1021.8 & 0.1 & 7.3 & 7.46 \\
\hline
\end{tabular}

$f$ is 0.2 for torsion spring $\mathrm{F} 0.2$. 
Figures 3 and 4 show the $\tau-\dot{\gamma}$ and $\mu-\dot{\gamma}$ results respectively for the two polymer fluids on log-log plots. It can be seen that the power-law model (Eqs. 3 and 5) can reproduce the behavior of both fluids satisfactorily over the entire shear-rate range of between 5 and $1022 \mathrm{~s}^{-1}$. The Bingham plastic model will not be able to achieve this level of goodness of fit.

a)

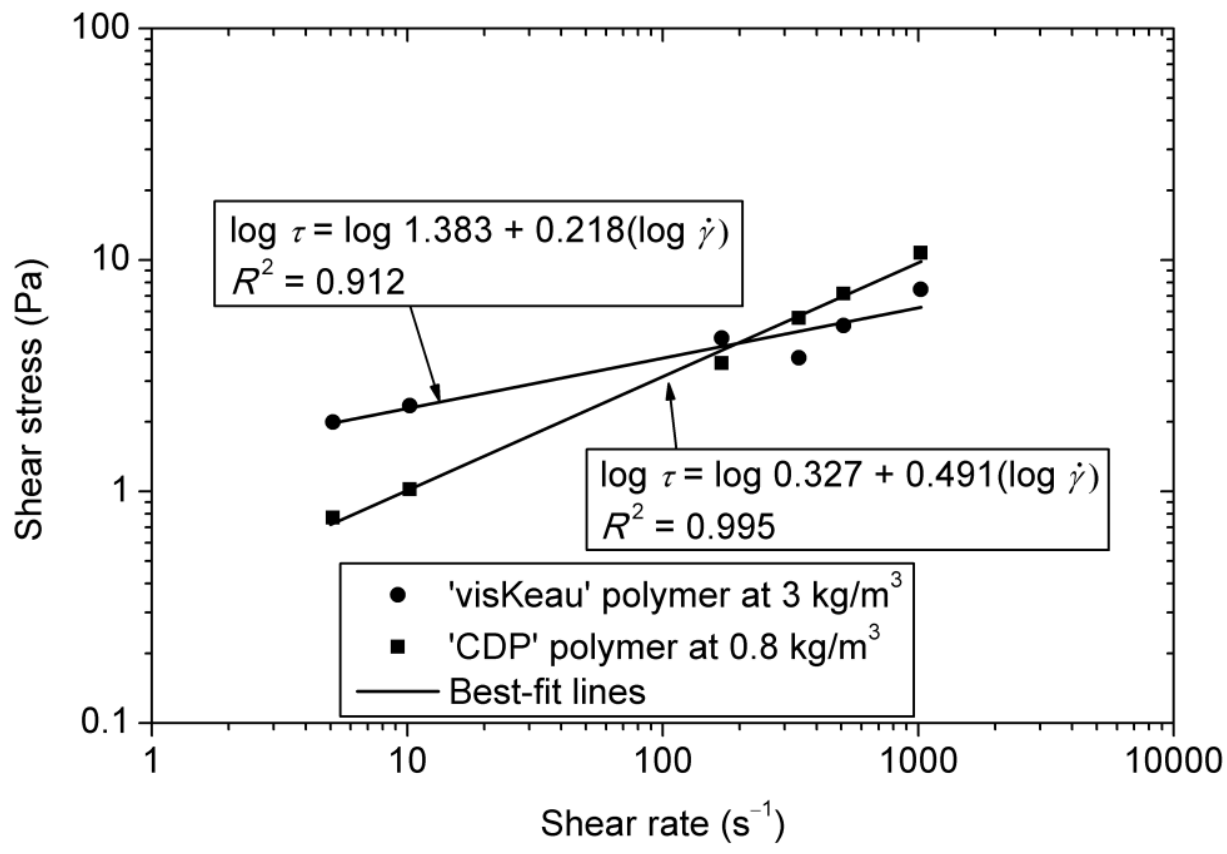

b)

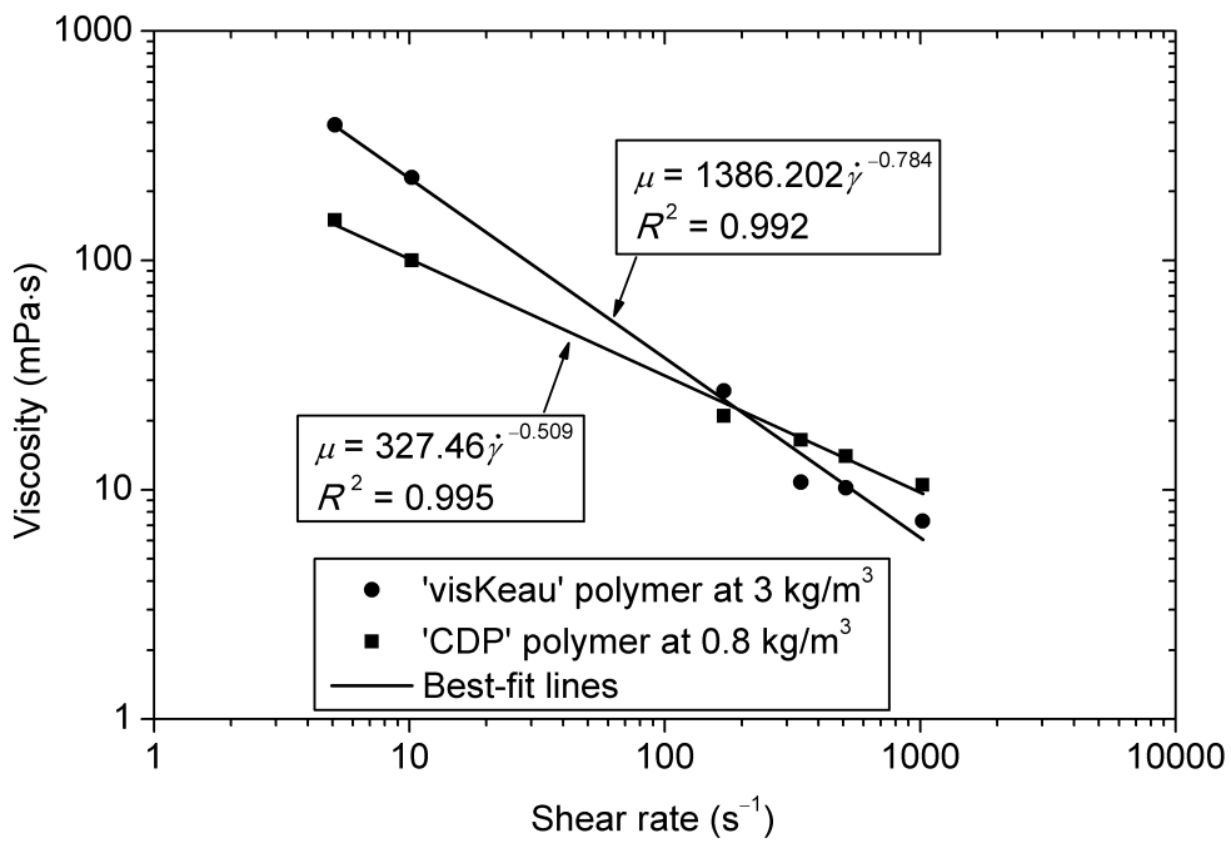

FIG. 3. Direct-indicating viscometer test results and interpretation for two polymer support fluids: a) shear stress versus shear rate; b) viscosity versus shear rate. 


\section{CONCLUSIONS}

With the advent of innovative fluid technology, deep excavations around the world are now commonly constructed using polymer support fluids. These fluids behave very differently to the traditional bentonite slurries but there is currently no standard way of presenting and interpreting viscometer data for them. Current guidelines are also not clear about the selection of appropriate rheological models. To improve the current situation, this paper has summarized conversion factors which can be used to present the viscometer results in SI units. Basic rheological concepts and simplified equations for quick estimations of rheological model parameters are given for those who are unfamiliar with the topic. By using the viscometer results of two polymers, the usefulness of the power-law model has also been demonstrated on both $\tau-\dot{\gamma}$ and $\mu-\dot{\gamma}$ plots. However, it should be noted that the analyses presented in this paper have been limited to viscosity measurements over the shear-rate range of the standard direct-indicating (Fann) viscometer, i.e., between 5 and $1022 \mathrm{~s}^{-1}$. Further work is in progress to assess the suitability of the power-law and other models for typical polymers solutions used in construction at shear rates beyond this shear-rate range.

\section{REFERENCES}

Ata, A. and O'Neill, M. (1997). "Characterization of the effect of POLY-BORETM polymer on the construction and performance of drilled shaft foundations. Phase I: field tests." Report to Baroid Drilling Fluids, University of Houston, Texas, 151 p.

Ata, A.A. and O'Neill, M.W. (1998). "Side-wall stability and side-shear resistance in bored piles constructed with high-molecular-weight polymer slurry." Proc., $3^{\text {rd }}$ Int. Geotech. Seminar on Deep Foundations on Bored and Auger Piles, Balkema, Rotterdam: 111-117.

Beresford, J.J., Cashman, P.M., and Hollamby, R.G. (1989). "The merits of polymeric fluids as support slurries." Proc., $3^{\text {rd }}$ Int. Conf. on Deep Foundations, Balkema, Rotterdam: 3-10.

Brown, D.A., Turner, J.P., and Castelli, R.J. (2010). "Drilled shafts: construction procedures and LRFD design methods." Publication No. FHWA NHI-10-016, Federal Highway Administration, U.S. Department of Transportation, Washington, D.C., $970 \mathrm{p}$.

Caenn, R., Darley, H.C.H., and Gray, G.R. (2011). Composition and properties of drilling and completion fluids, $6^{\text {th }}$ Ed., Gulf Professional Publishing, Oxford, 701 p.

Fann Instrument Company (2013). Model 35 Viscometer Instruction Manual, Fann Instrument Company, Houston, Texas, $44 \mathrm{p}$.

Federation of Piling Specialists (2006). Bentonite support fluids in civil engineering, $2^{\text {nd }}$ Ed., Federation of Piling Specialists, Kent, 27 p. 
Goodhue, K.G., Jr. and Holmes, M.M. (1995). Earth support fluid composition and method for its use, U.S. Patent 5,407,909, Apr. 18, 1995.

Jefferis, S.A. and Lam, C. (2013). "Polymer support fluids: use and misuse of innovative fluids in geotechnical works." Proc., 18 ${ }^{\text {th }}$ Int. Conf. on Soil Mech. and Geotech. Engrg., Presses des Ponts, Paris: 3219-3222.

Kheng, H., Bloomquist, D., Townsend, F.C., Thompson, P.Y. and Dobson, E. (1991). "Slurry performance in drilled shaft construction." Final Report to the Florida Department of Transportation, Department of Civil Engineering, University of Florida, Gainesville, FL, 242 p.

Lam, C., Jefferis, S.A., and Goodhue, K.G., Jr. (2010). "Observations on viscosity reduction of PHPA polymer support fluids." Proc., GeoShanghai 2010, GSP No. 205, ASCE, Reston, VA: 184-191.

Lam, C., Martin, P.J., Jefferis, S.A., and Goodhue, K.G., Jr. (2014). "Determination of residual concentration of active polymer in a polymeric support fluid." Geotech. Test. J., 37(1), 46-59.

Majano, R.E., O’Neill, M.W., and Hassan, K.M. (1994). "Perimeter load transfer in model drilled shafts formed under slurry." J. Geotech. Eng., 120(12), 2136-2154.

O’Neill, M.W. and Reese, L.C. (1999). "Drilled shafts: Construction procedures and design methods." Publication No. FHWA-IF-99-025, Federal Highway Administration, U.S. Department of Transportation, Washington, D.C., 758 p.

Savins, J.G. and Roper, W.F. (1954). "A direct-indicating viscometer for drilling fluids." Proc., API Drilling and Production Practice, American Petroleum Institute: $7-22$.

\section{APPENDIX}

Data from the Fann Instrument Company, Model 35 viscometer instruction manual:

$$
\begin{aligned}
& 1 \text { dial division }=0.511 \mathrm{~Pa}\left(\mathrm{~N} / \mathrm{m}^{2}\right)=5.11 \text { dynes } / \mathrm{cm}^{2} \text { (shear stress, } \tau \text { ) } \\
& 1 \mathrm{r} / \mathrm{min}(\mathrm{rpm})=1.703 \mathrm{~s}^{-1} \quad(\text { shear rate, } \dot{\gamma}) \\
& \mu=\frac{\tau}{\dot{\gamma}}=\frac{5.11}{1.703}=3.00 \text { poise }\left(\text { dynes } \cdot \mathrm{s} / \mathrm{cm}^{2}\right) \text { per degree per } \mathrm{r} / \mathrm{min} \\
& \therefore \mu=300 \text { centipoise per degree per } \mathrm{r} / \mathrm{min}=\frac{300 \times \theta}{\omega}
\end{aligned}
$$

